\title{
Design of Dam Concrete Pressure Sensor and its Application in Test
}

\author{
Keke Zhu $^{1, a}$, Yongdu Chen ${ }^{1, b}$, Shiyue Wang ${ }^{1, c}$, Liang Wu ${ }^{2, d}$ \\ ${ }^{1}$ Faculty of Civil Engineering and Mechanics, Kunming University of Science and Technology, \\ Kunming, China \\ ${ }^{2}$ Faculty of Electric Power Engineering, Kunming University of Science and Technology, Kunming, \\ China \\ azhukeke@outlook.com, b1120504974@qq.com, cynkmwsy@126.com, dkmu-wl@163.com
}

Keywords: sensor; dam concrete; deformation modulus.

Abstract. In this paper, through the compressive test of three graded dam concrete, using the method of strain electric testing, recording the value of stress and strain synchronously. A new strain sensor which was designed and processed is proved that is cheap, convenient, and can be used widely.

\section{Introduction}

Dam concrete is one of the most important construction materials in hydroelectric projects, large hydroelectric projects especially. Concrete dam has good "structural safety, durability, workability and Environment friendly", on the current building materials, due to the good performance of concrete and its low cost, there is no other building materials can replace the dam concrete as hydraulic engineering materials so far. China had built hundreds of huge and medium concrete dams nearly 30 years, which some of dams use concrete more than 1000 million cubic meters, such as the Yangtze River Gezhouba project and Taiwan Techi dam (the dam is 180 meters high). In addition, concrete also have a large number of applications in ports, irrigations and underground waterproof projects. If the hydroelectric project can be long-term security serviced, not only affects the economic benefit of the project, but also river flood controlled. Once the dam is destroyed, it will cause great damage to people's life, property and the environment, so its safety is an important event of public security. Its security problem has become a frontier issue of dam engineering technology. DH3817 dynamic strain instrument, can be used to synchronize the force and strain, is used in this study to measure a strain type pressure sensor which designed for this study. It can achieve the whole process real time acquisition and analysis of the stress and strain of dam concrete compressive and flexural strength.

\section{Design Strain Pressure Sensor}

Sensor Structure Form The column type sensor is a resistive strain test method. It can be used for high tonnage weighing, which is used widely in the social life. But price of a common sensor is relative high in the market, a self-made sensor is cheap, and we can also produce different forms, different uses of the sensor according to different actual needs, only if its performance was good enough.

Determine Sensor Size and Distribution Plan Design a pressure sensor which can withstand the axial load of $6000 \mathrm{kN}$, the safety factor is: $\mathrm{n}=1.8, \mu=0.27, \mathrm{E}=200 \mathrm{GPa}$. Determination of linearity, sensitivity, so that it can meet the practical requirements. choose $\mathrm{f}<400 \mathrm{~N} / \mathrm{mm}^{2}$, the impact bearing steel 45 , select $\mathrm{f}=300 \mathrm{~N} / \mathrm{mm}^{2}$, the inner diameter is $200 \mathrm{~mm}$ in the hollow cylindrical sensor.

$$
\begin{aligned}
& \sigma \leq[\sigma] \\
& {[\sigma]=\frac{\mathrm{F}}{\mathrm{A}} \leq \mathrm{f}=300 \mathrm{~N} / \mathrm{mm}^{2}}
\end{aligned}
$$

So select $A=21667 \mathrm{~mm}^{2}, \quad A=21667 \times 1.8=390176 \mathrm{~mm}^{2}$

Because $\frac{\pi}{4}\left(D^{2}-d^{2}\right)=A$, choose the height of the sensor is $300 \mathrm{~mm}$ with the outside diameter of 
sensor is $300 \mathrm{~mm}$.

$$
\begin{aligned}
& \sigma=\frac{\mathrm{F}}{\mathrm{A}}=\frac{6500 \times 10^{3}}{39250 \times 10^{-6}} \mathrm{~Pa}=165.6 \mathrm{MPa} \\
& \varepsilon=\frac{\sigma}{E}=\frac{165.6 \times 10^{6}}{200 \times 10^{9}}=828 \mu \varepsilon
\end{aligned}
$$

Total output strain:

$$
\varepsilon_{i}=2(1+\mu) \varepsilon=2103 \mu \varepsilon
$$

Sensitivity:

$$
\mathrm{K}=\frac{\Delta \varepsilon_{i}}{\Delta p}=\frac{2103}{6500} \mu \varepsilon / k N=0.324 \mu \varepsilon / k N
$$

So, the design of the strain pressure sensor's inner diameter is $30 \mathrm{~cm}$, outside diameter is $20 \mathrm{~cm}$, the height is $30 \mathrm{~cm}$. The design drawings of the sensor is shown in Fig. 1, the bridge mode is shown in Fig. 2, the distribution plan of the strain gauge is shown in Fig. 3, the sensor is shown in Fig. 4.

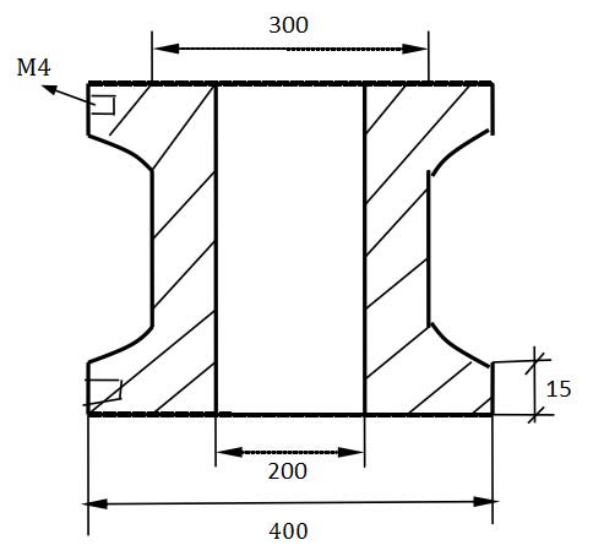

Fig. 1 The design drawings of the sensor

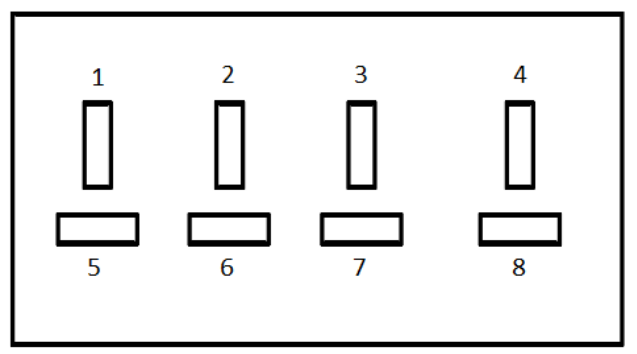

Fig. 3 the distribution plan of the strain gauge

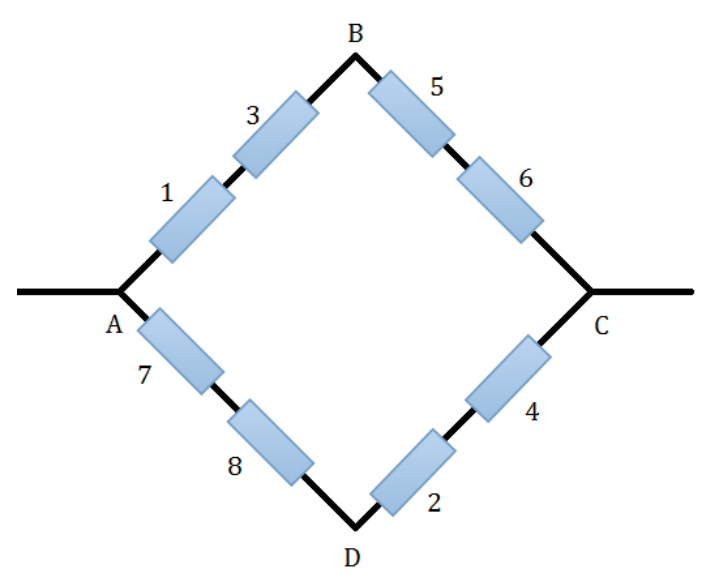

Fig. 2 the bridge mode

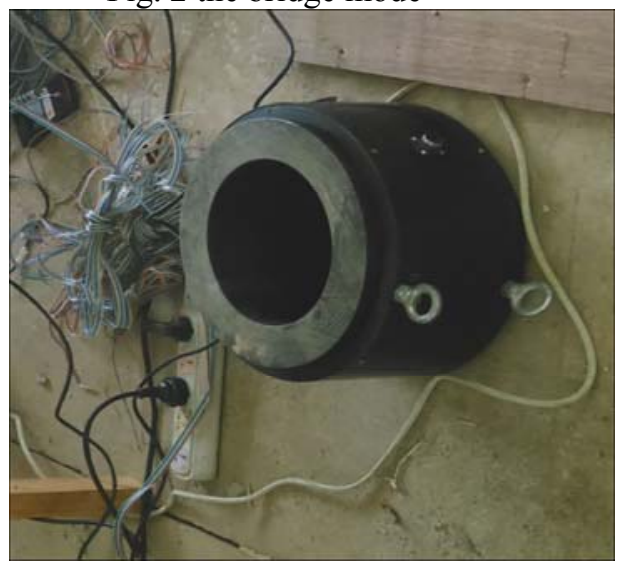

Fig. 4 the photo of the sensor

\section{Calibration of the sensor}

The sensor is calibrated with 1000t hydraulic press. Put the sensor into the press, then load the sensor with the press, and the data of the strain is collected by DH3817 dynamic strain instrument. The calibrate data of the sensor is shown in Table 1. 
Table 1 the calibrate data of the sensor

\begin{tabular}{cccc}
\hline $\begin{array}{c}\text { Force } \\
(\mathrm{kN})\end{array}$ & $\begin{array}{c}\text { Strain } \\
(\mu \varepsilon)\end{array}$ & $\begin{array}{c}\text { Force } \\
(\mathrm{kN})\end{array}$ & $\begin{array}{c}\text { Strain } \\
(\mu \varepsilon)\end{array}$ \\
\hline 200 & 91.6 & 2200 & 809.0 \\
400 & 175.2 & 2400 & 871.9 \\
600 & 252.0 & 2600 & 933.0 \\
800 & 329.6 & 2800 & 1007.0 \\
1000 & 402.8 & 3000 & 1062.0 \\
1200 & 472.4 & 3200 & 1124.3 \\
1400 & 524.0 & 3400 & 1190.0 \\
1600 & 607.9 & 3600 & 1248.8 \\
1800 & 673.8 & 3800 & 1311.0 \\
2000 & 743.7 & 4000 & 1377.0 \\
\hline
\end{tabular}

Fig. 5 is the relationship between the given force and the output strain, it can be seen that the output strain and force is linear from table 1 and figure 5. Using linear fitting curve is

$$
\begin{aligned}
& \mathrm{y}=0.3337 x+59.476 \\
& \Delta Y=-0.000011 x^{2}+0.3790 x+26.262-(0.3337 x+59.476)=-0.000011 x^{2}+0.0453 x-33.214 \\
& \Delta \mathrm{Y}_{1 \max }=13.42 \\
& \mathrm{e}_{z}=\frac{\Delta Y_{2 \max }}{Y_{F_{s}}}=1.7 \%
\end{aligned}
$$

Where: $\mathrm{e}_{z}$ is degree of linearity.

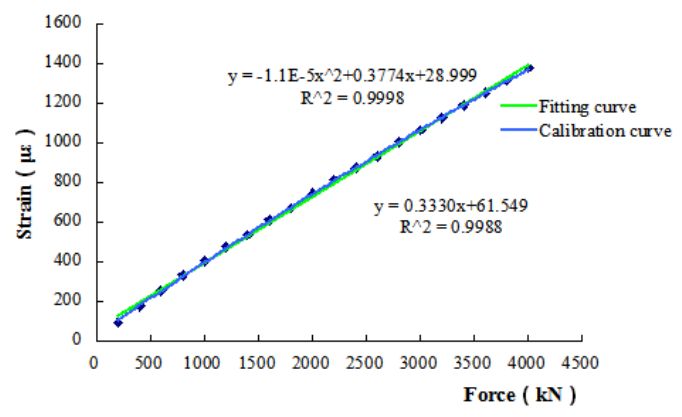

Fig. 5 the sensor's strain-force curve

The sensitivity of the sensor can be known from the fitting curve.

$\mathrm{K}=0.3337 \mu \varepsilon / k N$

There is a certain difference between the theoretical value of " $K=0.324 \mu \varepsilon / k N$ " and the theoretical value, but the difference is small, this is mainly caused by the difference of the processing size, but the accuracy is still in the first level.

\section{Application}

According to GB 50010-2010<Code for design of concrete structures $>$, the specimen is made of the size of $300 \mathrm{~mm} \times 300 \mathrm{~mm} \times 600 \mathrm{~mm}$. Under standard curing condition $\left(20 \pm 2{ }^{\circ} \mathrm{C}\right.$, relative humidity $95 \%$ above), maintenance to 28 days of age, the mix proportion of concrete is in Table 2. 
Table 2 Mix proportion of concrete

\begin{tabular}{|c|c|c|c|c|c|c|c|}
\hline \multirow[t]{2}{*}{$\begin{array}{c}\text { Water } \\
\left(\mathrm{kg} / \mathrm{m}^{3}\right)\end{array}$} & \multirow[t]{2}{*}{$\begin{array}{l}\text { Cement } \\
\left(\mathrm{kg} / \mathrm{m}^{3}\right)\end{array}$} & \multirow[t]{2}{*}{$\begin{array}{l}\text { Fly ash } \\
\left(\mathrm{kg} / \mathrm{m}^{3}\right)\end{array}$} & \multirow{2}{*}{$\begin{array}{l}\text { Mechani } \\
\text { sm sand } \\
\left(\mathrm{kg} / \mathrm{m}^{3}\right)\end{array}$} & \multirow{2}{*}{$\begin{array}{l}\text { Natural } \\
\text { sand } \\
\left(\mathrm{kg} / \mathrm{m}^{3}\right)\end{array}$} & \multicolumn{3}{|c|}{$\begin{array}{l}\text { Crushed stone (different size) } \\
\qquad\left(\mathrm{kg} / \mathrm{m}^{3}\right)\end{array}$} \\
\hline & & & & & $\begin{array}{c}5.0 \sim 20 \\
\mathrm{~mm}\end{array}$ & $\begin{array}{c}20 \sim 40 \\
\mathrm{~mm}\end{array}$ & $\begin{array}{c}40 \sim 80 \\
\mathrm{~mm}\end{array}$ \\
\hline 97.2 & 215 & 55 & 407.9 & 242.3 & 393.7 & 426.0 & 568.0 \\
\hline
\end{tabular}

this test use 5 prism of concrete, Three of them take the axial compression test, loading to the specimen until it is damaged, and measure the elastic modulus under elastic stage and the ultimate load; the last two specimen take the compressive modulus test. First loading to stress about $0.5 \mathrm{MPa}$ initial load, maintained for about 60 seconds and take the one third ultimate compressive strength as the compressive elastic modulus test of loading standard. Keep about 90 seconds, unloading to the original load with the same loading speed, then loading and unloading 3 times ibid, continue loading until the specimen is damaged with the same speed and measure the ultimate load. So we can get the stress-strain curve (see in Fig. 6).

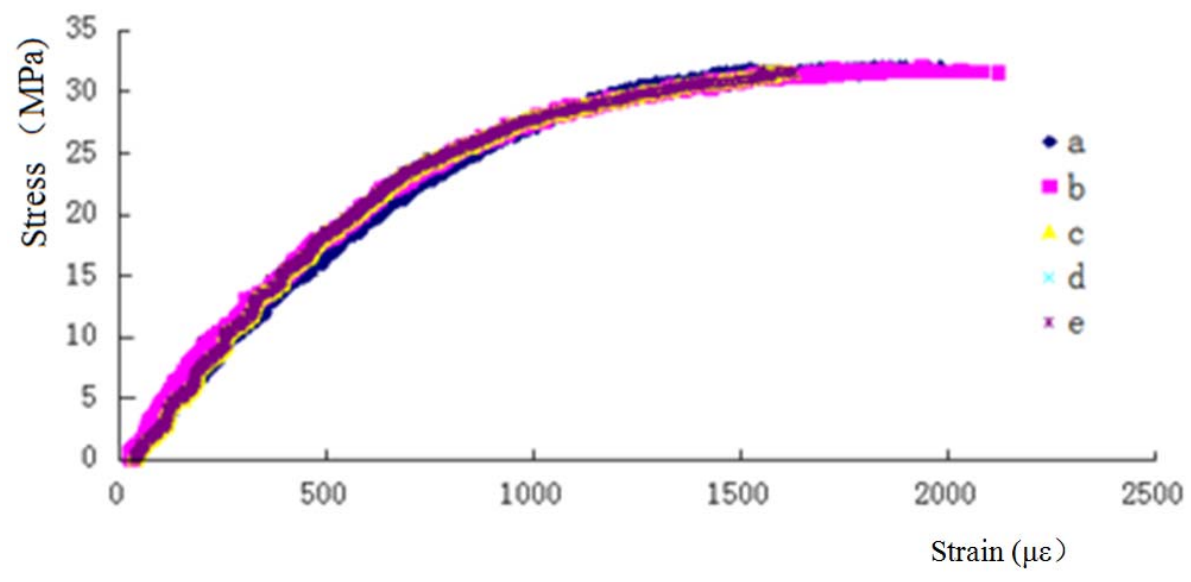

Fig. 6 the stress-strain curve

It can be seen that the strain pressure sensor can be used to collect the data of synchronous record the stress and strain with the DH3817 dynamic strain instrument through the stress-strain curve of Fig. 6. It can be seen that the strain pressure sensor can be used to collect the data of synchronous record the stress and strain with the DH3817 dynamic strain instrument through the stress-strain curve of Fig. 6. This can make the whole process analysis of concrete and grasp each stage of the damage condition of the dam concrete. then we can analysis the mechanical properties of dam concrete better.

\section{Conclusions}

The design and manufacture of the strain pressure sensor has the advantages of simple structure, easy processing, low cost and high accuracy. has higher engineering value.

\section{References:}

[1] GUO Encong, WANG Shiyue, HE Youchao, YUAN Mei: Design of special sensor for deformation modulus testing on plastic concrete, Concrete, Number 6 in 2013 (In China);

[2] Byung-Wan Jo,Young-Hyun Shon,Young-Jin Kim. The Evalution Of Elastic Modulus for 
Steel Fiber Reinforced Concrete[J]. Russian Journal of Nondestructive Testing . 2001 (2)

[3] Hou Jie, Cheng Heming, Wang Shiyue, TianFang, Experimental study on the fatigue elastic modulus of steel fiber reinforced Prestressed concrete slabs, CHINA CIVIL ENGINEERING JOURNAL, Vol.39 No.11 Nov. 2006 